DE

M E D I C I N A

T R O P I C A L

$\mathrm{DE}$

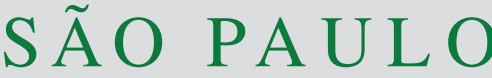

JOURNAL OF THE SÃO PAULO INSTITUTE OF TROPICAL MEDICINE

(1)Universidade Federal da Bahia, Faculdade de Farmácia, Serviço de Imunologia das Doenças Infecciosas, Salvador, Bahia, Brazil

(2) Universidade Federal da Bahia, Faculdade de Farmácia, Laboratório de Parasitologia Clínica, Salvador, Bahia, Brazil

Correspondence to: Maria Virginia Avelar Universidade Federal da Bahia, Faculdade de Farmácia, Serviço de Imunologia das Doenças Infecciosas, Rua Barão de Jeremoabo, s/n, Campus de Ondina, CEP 40170-115, Ondina, Salvador, BA, Brazil

E-mail: mvavelar@ufba.br

Received: 26 June 2017

Accepted: 26 October 2017

\section{Association between seroprevalence of IgG anti-Toxoplasma gondii and risk factors for infection among pregnant women in Climério de Oliveira Maternity, Salvador, Bahia, Brazil}

\author{
Maria Virginia Avelar ${ }^{1}$, Victor Otero Martinez ${ }^{1}$, Daniel Lima de Moura ${ }^{1}$, Indira \\ Alves Barros ${ }^{1}$, Anderson Alves da Silva Primo', Alan Oliveira Duarte', Neci \\ Matos Soares ${ }^{2}$, Fernanda Washington de Mendonça Lima ${ }^{1}$
}

\section{ABSTRACT}

Maternal Toxoplasma gondii (T. gondii) infection can lead to spontaneous abortion, fetal malformation, and numerous sequelae in the newborn, including visual and hearing impairment. T. gondii serology was determined in pregnant women and their newborns who were referred to Climério de Oliveira Maternity, Federal University of Bahia, and the possible associations with the risk factors for maternal infection were investigated. This cross-sectional study was conducted from January to December 2014 and included 712 pregnant women, aged 15 to 49 years, and 235 newborns. Seroprevalence was determined by the detection of T. gondii-specific immunoglobulin ( $\operatorname{Ig}) \mathrm{M}(\operatorname{IgM})$ and $\operatorname{IgG}$ antibodies using enzyme-linked immunoassay. In addition, mothers completed a questionnaire that focused on socioeconomic aspects, and survey data were tabulated using the SPSS statistical software program (version 21.0 for Windows). The seroprevalence rate for specific IgG antibodies was 51\% (362) among mothers and 93\% (219) among neonates. All the mothers and their newborns were negative for specific-IgM antibodies. Higher age group and lower maternal education were the only risk factors statistically associated with the presence of specific IgG. In summary, high levels of specific IgG antibodies were observed in pregnant women. The knowledge of risk factors for toxoplasmosis can help in the orientation of newly pregnant women.

KEYWORDS: Toxoplasmosis. Prevalence. Infection. Pregnant women.

\section{INTRODUCTION}

The protozoan Toxoplasma gondii (T. gondii), causative agent of toxoplasmosis, was first identified at the Pasteur Institute in Tunis, Tunisia, by the French researchers Nicolle and Manceaux and in Brazil by Splendore, in 1908, according to Weiss and Dubey ${ }^{1}$. This intracellular parasite can infect different tissues in a variety of vertebrate animals, including humans ${ }^{2}$. The ability of this parasite to multiply within all nucleated cells of hosts is noteworthy ${ }^{3}$. Members of the Felidae family are considered definitive hosts, whereas birds, livestock, and the great majority of homoeothermic vertebrates are intermediate hosts ${ }^{4}$. In addition to being a zoonosis, toxoplasmosis is a systemic infectious disease. It is associated with all continents and most types of climate, with a higher prevalence in hot and humid climate $^{5}$. This infection can be transmitted by the passage of one of the forms of T. gondii (i.e., oocysts, bradyzoites, and trophozoites) through inhalation, ingestion, transfusion, and organ transplantation from one individual to another or vertically from the infected mother to the fetus or newborn ${ }^{6}$. Depending on the immunological 
competence of the host, signs and symptoms may range from absent to severe. Immunocompetent individuals usually present an initial or acute phase of asymptomatic disease ${ }^{7}$. The percentage of these individuals varies between $80 \%$ and $90 \%$. Nevertheless, in immunocompromised individuals, disease manifestations can be severe ${ }^{8}$.

The occurrence of a $T$. gondii infection during gestation deserves special attention from public health agencies, whether individually or collectively. Pregnant women who are $T$. gondii seronegative raise the greatest concern. A first-time $T$. gondii infection during the gestational period without the protection of specific $\operatorname{IgG}$ antibodies may compromise embryogenesis, fetal development and increase neonatal morbidity and mortality. According to Higa et al. ${ }^{9}$, the prevalence of infection in the population and the frequency of contacts with possible sources of contamination are factors associated with acquisition of the infection. Remington et al. ${ }^{10}$ have suggested the possibility of vertical transmission of toxoplasmosis resulting from a reactivation of the disease in chronically infected mothers caused by the expressive reduction of immunity. Immunocompetent people are usually asymptomatic. Thus, infection in pregnant women often goes undetected, and a possible maternal-fetal transmission may be recognized with the appearance of early or late sequelae in the neonate ${ }^{11}$.

This work aimed to establish the seroprevalence for toxoplasmosis in mothers and their respective newborns who were referred to the Climério de Oliveira Maternity (MCO), Federal University of Bahia (Salvador-Bahia), Brazil, from January to December 2014, and to associate maternal seroprevalence with risk factors of infection.

\section{MATERIAL AND METHODS}

The present study is part of a project entitled "Agents of congenital infection in pregnant women in Salvador, Bahia: research on the prevalence and analysis of risk factors." This study was approved by the Ethics Committee of the Federal University of Bahia (UFBA), School of Nursing, in 2013, under the protocol $\mathrm{N}^{\circ} 384.209$.

This cross-sectional study was carried out from January to December 2014 at the Climério de Oliveira Maternity, UFBA, Salvador, Bahia. The study participants were 712 pregnant women from Salvador and other municipalities in the State of Bahia, assisted by the Unified Health System (SUS), and 235 newborn infants (NB) from seropositive mothers. Pregnant women with insufficient blood samples to perform tests were excluded from the study.

Pregnant women were informed on the nature of the study and those who agreed to participate signed the consent form and completed the questionnaire addressing socioeconomic aspects and risk factors of contracting T. gondii infection.

For the detection of IgG antibodies, a third-generation indirect enzyme-linked immunoassay (recombinant antigen) was used, and $\operatorname{IgM}$ was detected according to the manufacturer's instructions (Symbiosys, Leme, State of São Paulo, Brazil). Optical densities were measured by using the $450-\mathrm{nm}$ and $630-\mathrm{nm}$ filters and the ALISEI automated system (Seac Radim, Italy).

After data tabulation, SPSS statistical software (version 21.0 for Windows) was used for analyses. The normality of continuous data was evaluated using the KolmogorovSmirnov test. The chi-square test was used for comparisons between proportions, and the level of statistical significance was set at $\mathrm{p} \leq 0.05$.

\section{RESULTS}

All the participants ( 712 pregnant women aged 15 to 49 years and 235 newborns) presented negative anti-T. gondii IgM antibodies. Of the total maternal sera analyzed, 362 were positive for specific $\operatorname{IgG}$ and 350 were negative, resulting in a seroprevalence rate of $51 \%$.

Among two hundred and thirty-five newborns of seropositive mothers, IgG anti-T. gondii was positive in $219(93 \%)$ and negative in 16 (7\%).

Table 1 shows that the presence of anti-T. gondii antibody was positively associated with the level of education and the age group of pregnant women who participated in the study.

\section{DISCUSSION}

The seroprevalence of $51 \%$ for $T$. gondii infections found in pregnant women is consistent with the results of Dubey et al. ${ }^{12}$. These authors mentioned a variation of anti-T. gondii IgG seroprevalence in pregnant women, in the Brazilian regions, ranging from $50 \%$ to $80 \%$. In 2002, Nascimento et al. ${ }^{13}$ carried out a study in pregnant women who attended SUS in Salvador, came from different cities of Bahia and reported a seroprevalence of $64.9 \%$. However, the seroprevalence in pregnant women from Porto Alegre was $59.8 \%$ as reported in 2003 by Varella et al $^{14}$. In 2012, in the city of Aracaju, Sergipe, Tavares et al. ${ }^{15}$ reported a IgG anti-T. gondii seroprevalence of $43.5 \%$ in pregnant women who attended SUS, which was a much lower rate than the ones reported by previously mentioned studies. Prevalence rates also differ between countries. Flatt and Shetty ${ }^{16}$ reported, in a study published in 2012, an IgG seroprevalence rate of $17.32 \%$ for $T$. gondii in pregnant 
Table 1 - Anti-T. gondii IgG in pregnant women versus risk factors for infection

\begin{tabular}{|c|c|c|c|c|c|}
\hline \multirow{2}{*}{ Risk factors for infection by $T$. gondii } & \multicolumn{5}{|c|}{ Dosage IgG anti-T. gondii } \\
\hline & Positive & Negative & Total & OR $(95 \% \mathrm{Cl})$ & $p$-value \\
\hline Do you breed dogs and/or cats? & & & & & 0.365 \\
\hline Yes & $182(51.6 \%)$ & $171(48.8 \%)$ & 353 & & \\
\hline No & $168(48.1 \%)$ & $181(51.9 \%)$ & 349 & & \\
\hline Do you consume undercooked meat? & & & & & 0.678 \\
\hline Yes & $88(58.5 \%)$ & $84(48.8 \%)$ & 172 & & \\
\hline No & $264(49.3 \%)$ & $269(50.7 \%)$ & 531 & & \\
\hline Contact with soil / manure? & & & & & 0.170 \\
\hline Yes & $86(58.5 \%)$ & $61(41.5 \%)$ & 147 & & \\
\hline No & $264(47.5 \%)$ & $292(52.5 \%)$ & 556 & & \\
\hline \multicolumn{6}{|l|}{ Education } \\
\hline Complete 3rd grade & $12(38.7 \%)$ & $19(61.3 \%)$ & 31 & & \\
\hline Incomplete 3rd grade & $19(38.8 \%)$ & $30(61.2 \%)$ & 49 & & 0.995 \\
\hline Complete 2 nd grade & $159(49.1 \%)$ & $165(50.9 \%)$ & 324 & & 0.272 \\
\hline Inomplete 2 nd grade & $59(46.5 \%)$ & $68(53.5 \%)$ & 127 & & 0.497 \\
\hline Complete 1st grade & $25(46.3 \%)$ & $29(53.7 \%)$ & 54 & & 0.149 \\
\hline Incomplete 1st grade & $74(63.8 \%)$ & $42(36.2 \%)$ & 116 & & $0.010^{*}$ \\
\hline Illiterate & $2(100.0 \%)$ & $0(0.00 \%)$ & 2 & & 0.197 \\
\hline Family Income (minimum wage) & & & & & 0.330 \\
\hline$<1$ & $20(43.5 \%)$ & $26(56.5 \%)$ & 46 & & \\
\hline $1-3$ & $298(51.0 \%)$ & $286(49.0 \%)$ & 584 & & \\
\hline 4 a 6 & 30 (47.6\%) & 33 (52.4\%) & 63 & & \\
\hline$>6$ & $2(25.0 \%)$ & $6(75.0 \%)$ & 8 & & \\
\hline Place of residence & & & & & 0.331 \\
\hline Capital & $303(49.1 \%)$ & $314(50.9 \%)$ & 617 & & \\
\hline Interior & $46(54.8 \%$ & $38(45.2 \%)$ & 84 & & \\
\hline \multicolumn{6}{|l|}{ Age Range (years) } \\
\hline $15-24$ & $99(39.6 \%)$ & $151(60.4 \%)$ & 250 & Ref. & \\
\hline $25-34$ & $172(53.6 \%)$ & $149(46.4 \%)$ & 321 & $1.76(1.25-2.46)$ & $<0.010^{*}$ \\
\hline $35-44$ & $74(59.7 \%)$ & $50(40.3 \%)$ & 124 & $2.26(1.45-3.50)$ & $<0.010^{*}$ \\
\hline$\geq 45$ & 5 (62.5\%) & 3 (35.5\%) & 8 & $2.54(0.59-10.87)$ & 0.208 \\
\hline
\end{tabular}

Source: Research data. * Significant association $(p<0.05)$

women in London. In Kinshasa, the Democratic Republic of Congo, this rate was $80.3 \%$, according to the study of Yobi et al. ${ }^{17}$. The specific IgG seroprevalence reported by Yad Yad et al. ${ }^{18}$ in a study involving pregnant women in the Southern province of Khuzestan, Iran, was 27.3\%.

According to Yobi et al. ${ }^{17}$, the hygienic conditions in the environment contribute to a lesser or greater exposure to the parasite and, by extension, to the seroprevalence in each region.

As expected, in this study, there was a high seropositivity rate of anti- $T$. gondii IgG in the newborn infants of seropositive pregnant women (93\%) due to the passage of these maternal antibodies through transplacental routes.

The lack of the detection of anti-T. gondii IgM among the neonates indicates that there was no vertical transmission of toxoplasmosis. This finding is consistent with the fact that specific IgM was not detected in any of the pregnant women who participated in the study, an indicator of a T. gondii primary infection or reactivation, which could increase the risk of vertical transmission. Andrade et al. ${ }^{19}$ reported a case of vertical transmission in a mother who had retinochoroiditis due to $T$. gondii reactivation during 
the gestational period, representing a rare case of congenital infection.

In the analysis of the risk factors, an association between anti-T. gondii IgG seropositivity and dog and/or cat breeding was not demonstrated. Our finding corroborates data of Flatt and Shetty ${ }^{16}$, involving 2,610 pregnant women in the city of London, United Kingdom, and Porto et al. ${ }^{20}$, involving 503 pregnant women attending a maternity ward in Recife, State of Pernambuco, Brazil, between October 2004 and April 2005. Although Tavares et al. ${ }^{15}$ reported a positive association in a study involving 395 pregnant women from Aracaju, State of Sergipe, Brazil, who attended SUS in 2011.

The habit of ingesting undercooked meat was not a risk factor for toxoplasmosis, which agrees with the study of de Quadros et al..$^{21}$, involving 148 pregnant women. However, an outbreak of toxoplasmosis due to the ingestion of raw meat occurred in the city of São Paulo, State of São Paulo, Brazil, where six patients acquired acute toxoplasmosis, including a pregnant woman; despite maternal treatment, fetal death occurred ${ }^{22}$.

In our study, the habit of handling soil or manure did not constitute a risk factor for toxoplasmosis as evidenced by antibodies against $T$. gondii. The difference in the seropositivity of the pregnant women who handled these materials (58.5\%) and those who did not $(47.5 \%)$ was not statistically significant. A similar result was demonstrated in a study by Porto et al..$^{20}$ who reported that pregnant women who had a habit of handling soil (16.8\%) versus those who did not $(24.5 \%)$ did not generate a statistical significance $(\mathrm{p}=0.07)$.

Regarding the family income, the seropositivity of participants with a family income below one minimum wage $(43.5 \%)$ was similar to those whose income was greater than six minimum wages (25\%). A similar result was reported by Rhodes and Shetty ${ }^{16}$ but they argued that the difference was not statistically significant because only eight patients had income of more than six minimum wages. It was not possible to indicate in this research whether the family income increment would make a difference in this population.

As for the place of residence, Yad Yad et al. ${ }^{18}$ reported no significant differences in the specific $\operatorname{IgG}$ seroprevalence in a rural area $(\mathrm{p}<0.5)$ versus an urban area $(\mathrm{p}=0.06)$. These results are possibly due to the scarcity of studies involving these variables, given that most of the work is carried out in developed countries where social equality is more prevalent.

T. gondii seropositivity showed a negative association with educational level, with a decreasing tendency of seropositivity as the level of education increased (Table 1) and revealed a significant statistical correlation $(p=0.01)$. This finding is in line with the results of Varella et al. ${ }^{14}$ and Porto et $a l .{ }^{20}$ ( $\mathrm{p}=0.0013$ ); both studies demonstrated lower rates of toxoplasmosis seropositivity in pregnant women with eight or more years of education $(26.1 \%)$ than in those with up to seven years of study (12.6\%). On the other hand, de Quadros et al. ${ }^{21}$ demonstrated that there were no differences for specific $\operatorname{IgG}$ production among pregnant women who had not completed primary education compared to those who had completed high school. This divergence probably reflects differences in habits of the studied populations and the negative association could be explained by better hygiene habits and a consequent reduction in the degree of exposure to $T$. gondii. Pregnant women with a higher educational level have better access to information.

This study demonstrated a IgG anti-T. gondii seroprevalence of $51 \%$ in pregnant women and of $93 \%$ in their newborn infants. There was no detection of serological markers of primary maternal infection (IgM) in pregnant women included in the study. Among the neonates of these chronically infected mothers, none had anti-T. gondii IgM. Risk factors that had a statistically significant association with $T$. gondii infection were education level and age group. The fact that several risk factors were not associated with T. gondii infection might depend on characteristics and habits of different populations.

Besides contributing with important information about the vertical transmission of toxoplasmosis, risk factors involved and adoption of preventive measures, this study raises a question about the seronegative status of $7 \%$ of the newborn infants of IgG-positive mothers. Although IgG can cross the placenta, not all subclasses (e.g., IgG1, IgG2, IgG3, and IgG4) are equally efficient in this process; for example, $\mathrm{IgG} 2$ does not easily cross the placenta. This curious finding deserves further investigation. It is noteworthy that not all newborns of mothers seropositive for IgG anti-T. gondii tested positive for this serological marker. This finding shows that there is not always a transplacental transfer of maternal IgG to the fetus, which can be explained by the different structural and functional characteristics of $\operatorname{IgG}$ subclasses, such as the ability to cross the placenta. The IgG2 isotype is least effective at crossing the placental barrier. Although the lack of IgG maternal transmission to the fetus could be related to the antibody titer; that is, women who had higher IgG concentration would be more likely to generate a naturally acquired passive immunity in their newborns ${ }^{23}$. Future studies are needed to clarify these issues.

\section{ACKNOWLEDGEMENTS}

This study was funded by the State of Bahia Research Foundation (FAPESB), Grant Agreement N ${ }^{\circ}$ SUS0037/2013, Notice 020/2013. 


\section{REFERENCES}

1. Weiss LM, Dubey JP. Toxoplasmosis: a history of clinical observations. Int J Parasitol. 2009;39:895-901.

2. Rorman E, Zamir CS, Rilkis I, Ben-David H. Congenital toxoplasmosis - prenatal aspects of Toxoplasma gondii infection. Reprod Toxicol. 2006;21:458-72.

3. Pfaff AW, Georges S, Abou-Bacar A, Letscher-Bru V, Klein JP, Mousli M, et al. Toxoplasma gondii regulates ICAM-1 mediated monocyte adhesion to trophoblasts. Immunol Cell Biol. 2005;83:483-9.

4. Souza W, Belfort Jr R, organizadores. Toxoplasmose \& Toxoplasma gondii. Rio de Janeiro: Fiocruz; 2014.

5. Robert-Gangneux F, Dardé ML. Epidemiology of and diagnostic strategies for toxoplasmosis. Clin Microbiol Rev. 2012;25:26496.

6. Frenkel JK, Bermudez JE. Toxoplasmosis. In: Focaccia R, editor científico. Veronesi: tratado de infectologia. $4^{\mathrm{a}}$ ed. São Paulo: Atheneu; 2009. v. 2, p.1793-812.

7. Ferguson DJ, Bowker C, Jeffery KJ, Chamberlain P, Squier W. Congenital toxoplasmosis : continued parasite proliferation in the fetal brain despite immunological maternal control in other tissues. Clin Infect Dis. 2013; 56:204-8.

8. Nissapatorn V, Noor Azmi MA, Cho SM, Fong MY, Init I, Rohela $\mathrm{M}$, et al. Toxoplasmosis: prevalence and risk factors. J Obstet Gynaecol. 2003;23:618-24.

9. Higa LT, Araújo SM, Tsuneto L, Catilho-Pelloso M, Garcia JL, Santana RG, et al. A prospective study of Toxoplasma-positive pregnant women in southern Brazil: a health alert. Trans R Soc Trop Med Hyg. 2010;104:400-5.

10. Remington JS, Klein JO, Wilson CB, Nizet V, Maldonado YA, editors. Infectious diseases of the fetus and newborn infant. $7^{\text {th }}$ ed. Philadelphia: Elsevier Mosby Saunders; 2011.

11. McAuley JB. Congenital toxoplasmosis. J Pediatric Infect Dis Soc. 2014;3 Suppl 1:S30-5.

12. Dubey JP, Lago EG, Gennari SM, Su C, Jones JL. Toxoplasmosis in humans and animals in Brazil: high prevalence, high burden of disease, and epidemiology. Parasitology. 2012;139:1375424.

13. Nascimento I, Carvalho S, Cardozo N, Asfora S, Campos A, Menezes S, et al. Estudo da prevalência de anticorpos antiToxoplasma gondii em mulheres grávidas no Estado da Bahia. Rev Ci Med Biol. 2002;1:12-15.
14. Varella IS, Wagner MB, Darela AC, Nunes LM, Müller RW. Prevalência de soropositividade para toxoplasmose em gestantes. J Pediatr (Rio J). 2003;79:69-74.

15. Tavares MS, Araujo RM, Abud AC, Alves JA, Nunes MS, Inagaki AD. Toxoplasmosis in pregnant women: prevalence, risk factors and prevention actions. J Nurs UFPE On Line. 2012;6:1379-85.

16. Flatt A, Shetty N. Seroprevalence and risk factors for toxoplasmosis among antenatal women in London: a reexamination of risk in ethnically diverse population. Eur $\mathbf{J}$ Public Health. 2012;23:648-52.

17. Yobi D, Piarroux R, L'Ollivier C, Franck J, Situakibanza H, Muhindo $\mathrm{H}$, et al. Toxoplasmosis among pregnant women: high seroprevalence and risk factors in Kinshasa, Democratic Republic of Congo. Asian Pac J Trop Biomed. 2014;4:69-74.

18. Yad Yad MJ, Jomehzadeh N, Sameri MJ, Noorshahi N. Seropervalence of anti-Toxoplasma gondii antibodies among pregnant woman in South Khuzestan, Iran. Jundishapur J Microbiol. 2014;7:e9998.

19. Andrade GM, Vasconcelos-Santos DV, Carellos EV, Romanelli RM, Vitor RW, Carneiro AC, et al. Congenital toxoplasmosis from the chronically infected woman with reactivation of retinochoroiditis during pregnancy. J Pediatr (Rio J). 2010;86:85-8.

20. Porto AM, Amorim MM, Coelho IC, Santos LC. Perfil sorológico para toxoplasmose em gestantes atendidas em maternidade. Rev Assoc Med Bras. 2008;54:242-8.

21. Quadros RM, Rocha GC, Romagna G, Oliveira JP, Ribeiro DM, Marques SM. Toxoplasma gondii seropositivity and risk factors in pregnant women followed up by the Family Health Strategy. Rev Soc Bras Med Trop. 2015;48:338-42.

22. Eduardo MB, Katsuya EM, Ramos SR, Pavanello EI, Paiva OR, Brito SN, et al. Investigação do surto de toxoplasmose associado ao consumo de prato à base de carne crua ("steak tartar”), nos municípios de São Paulo e Guarujá, SP Novembro de 2006. Bol Epidemiol Paulista. 2007;4:1-7.

23. Dattoli VC, Veiga RV, Cunha SS, Pontes-de-Carvalho L, Barreto ML, Alcantara-Neves NM. Oocyst ingestion as an important transmission route of Toxoplasma gondii in Brazilian urban children. J Parasitol. 2011;97:1080-4. 